\title{
Conformational Analysis of [60]PCBM via Second-Order Proton NMR Spin-Spin Coupling Effects
}

\author{
Tong Liu, ${ }^{1}$ Isaac Abrahams, ${ }^{2}$ T. John S. Dennis ${ }^{1 *}$ \\ 1 School of Physics and Astronomy, Queen Mary University of London, Mile End Road, London, E1 \\ 4NS, UK. \\ 2 School of Biological and Chemical Sciences, Queen Mary University of London, Mile End Road, \\ London, E1 4NS, UK.
}

\section{Synthesis}

The synthesis of [60]PCBM was adapted from the method given from the discovery of [60]PCBM by Hummelen, Wudl, and co-workers $1995 .^{8}$ It involves three stages (1) esterification of commercially available 5-oxo-5-phenylpentanoic acid, which is then (2) converted into methyl 4-benzoylbutyrate $p$ tosylhydrazone and then (3) reacted with $\mathrm{C}_{60}$ to obtain [60]PCBM. The tosylhydrazone acts as a leaving group.

Stage 1: Synthesis of methyl-[5-oxo-5-phenyl] pentanoate

$25 \mathrm{~g}$ of 5-oxo-5-phenylpentanoic acid was dissolved in a mixture of $100 \mathrm{ml}$ of methanol and $250 \mathrm{ml}$ of benzene, after which $3.75 \mathrm{~g}$ of 4-methylbenzenesulfonic acid was added and refluxed for 18 hours. After cooling to room temperature, the reactant mixture dissolved in $250 \mathrm{ml}$ of ethyl acetate and washed three times with $200 \mathrm{ml}$ of $10 \%$ sodium carbonate solution to neutralize any unreacted acid. This was followed by another three washings, but this time with $200 \mathrm{ml}$ per wash of distilled water. The organic layer separated and dried with about $10 \mathrm{~g}$ of anhydrous magnesium sulphate. Finally, the solvents in the organic solvent were removed by rotary-evaporation leaving about $15 \mathrm{~g}$ an oily product.

Stage 2: Synthesis of methyl 4-benzoylbutyrate $p$-tosylhydrazone

The $15 \mathrm{~g}$ of methyl-[5-oxo-5-phenyl]pentanoate from Stage 1 together with $15.5 \mathrm{~g}$ of commercial 4methylbenzenesulfonohyzide were dissolved in $45 \mathrm{ml}$ methanol, then refluxed for 6 hours. The reaction mixture was then cooled to room temperature and allowed to stand for 24 hours. After which it was chilled to $-15^{\circ} \mathrm{C}$. The methanol was then removed by vacuum filtration and the resulting in crystals of methyl 4-benzoylbutyrate $p$-tosylhydrazone were washed with ice-cold methanol, and then dried in an oven at $50^{\circ} \mathrm{C}$. This gave about $10 \mathrm{~g}$ of colourless crystalline product.

\section{Stage 3: Synthesis of [60]PCBM}

Finally, $0.5 \mathrm{~g}$ of the methyl 4-benzoylbutyrate $p$-tosylhydrazone (per batch from stage 2) was dissolved in $10 \mathrm{ml}$ of dry pyridine in a three-neck round bottom flask under a dry nitrogen atmosphere. Then 36 $\mathrm{mg}$ of sodium methoxide was added and stirred for 20 minutes. Separately, $875 \mathrm{mg}$ of $\mathrm{C}_{60}$ was dissolved in $600 \mathrm{ml}$ of 1,2-dichlorobenzene and degassed. The degassed $\mathrm{C}_{60}$ solution was then added anaerobically to the pyridine solution, after which the mixture was heated to $85^{\circ} \mathrm{C}$ and irradiate with a $150 \mathrm{~W}$ sodium lamp for 18 hours while stirring. After cooling to room temperature, the crude [60]PCBM product was partially purified by column chromatography on silica gel (with partially reacted homo-fullerenes remaining on the column). The recovered [60]PCBM solution was filtered and then added to $500 \mathrm{ml}$ of methanol to precipitate the [60]PCBM - leaving the 1,2-dichlorobenzene and pyridine dissolved in the methanol. Finally, the precipitate was removed from the liquids by vacuum filtration and dried in an oven at $50^{\circ} \mathrm{C}$ for 3 hours. This three-step process gave about $0.5 \mathrm{~g}$ of a fine brown power of [60]PCBM, which was dissolved in HPLC-grade toluene for final purification by HPLC. 


\section{Purification}

The sample was further purified by HPLC using a Japan Analytical Industry LC908 machine in single pass mode in conjunction with a Waters Sunfire bare silica column $(19 \mathrm{~mm}$ i.d., $\times 150 \mathrm{~mm})$ and UV detection at $312 \mathrm{~nm}$. The toluene eluent flow rate was $18 \mathrm{ml} / \mathrm{min}$ with injections being $3 \mathrm{ml}$ of a $10 \mathrm{mg} / \mathrm{ml}$ toluene solution of the [60]PCBM obtained from the above method. The resulting chromatogram, Figure $\mathrm{S} 1$, indicates the presence of two components - unreacted $\mathrm{C}_{60}$ with a retention time of 2 minutes and [60]PCBM with a retention time of 4.5 minutes. The [60]PCBM is separated from $\mathrm{C}_{60}$ with more than a minute of baseline between them, indicating the HPLC purified [60]PCBM had negligible traces of impurities.

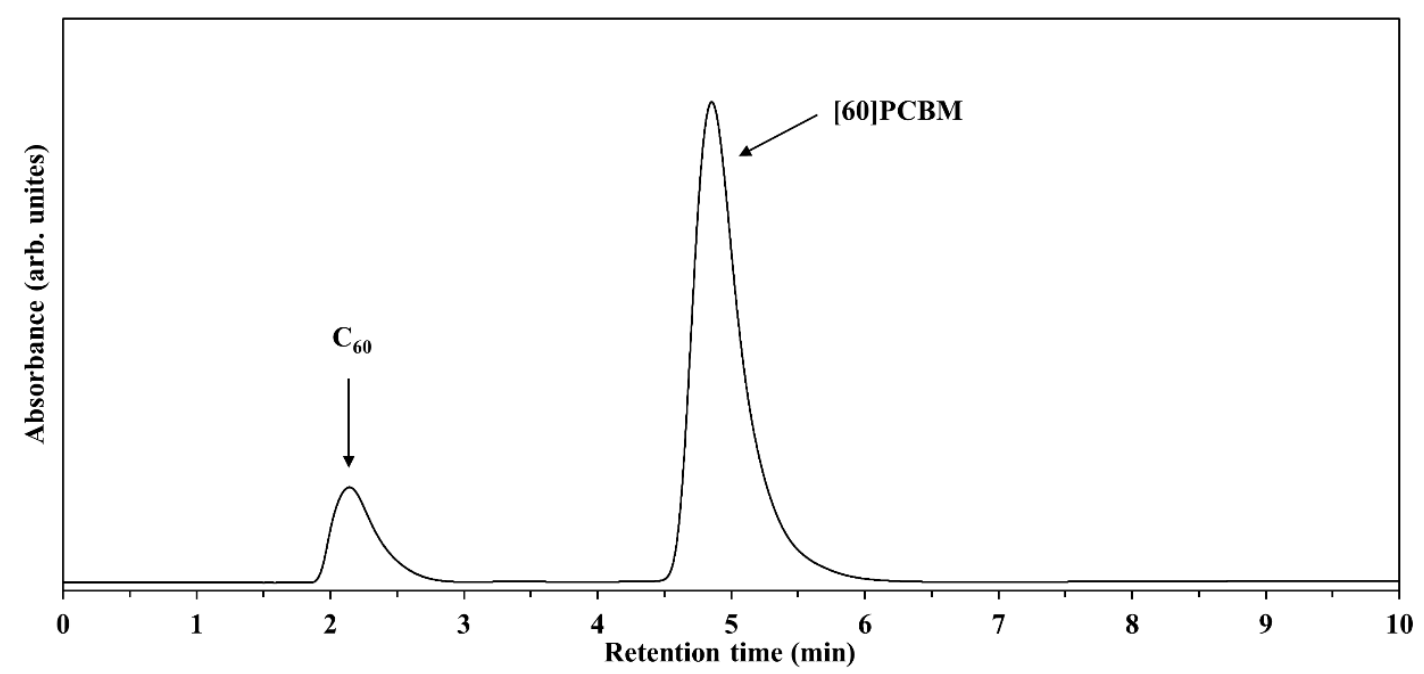

Figure S1. The HPLC chromatogram for the purification of [60]PCBM - indicating the purity of the sample.

\section{NMR data acquisition and Sample preparation}

After purification, toluene was removed from the [60]PCBM by rotary evaporation. [60]PCBM tenaciously retains solvents. As such, to remove residual toluene the [60]PCBM dissolved in about 20 $\mathrm{ml}$ of $\mathrm{CS}_{2}$, which was then removed by rotary evaporation. This process was repeated three times to minimize the amount of retained toluene. The [60]PCBM was then dissolved in $\mathrm{CS}_{2}$ to a concentration of about $5 \mathrm{mg} / \mathrm{ml}$. This is well below saturation and was done with the intention of ensuring the [60]PCBM was completely dissolved. The solution was then placed in a $5 \mathrm{~mm}$ diameter NMR tube. Before sealing the tube, three drops of d6-benzene were added to the tube to act as a signal lock.

The ${ }^{1} \mathrm{H}$ NMR spectrum was recorded at a temperature of $300 \mathrm{~K}$ on a Bruker AV600 spectrometer operating at $600 \mathrm{MHz} .16$ scans were co-added to produce the final spectrum. 